\title{
Defects in Si foils fabricated by spalling at low temperature: Electrical activity and atomic nature
}

\author{
A Masolin ${ }^{1}$, E Simoen $^{3}, \mathrm{~J} \mathrm{Kepa}^{2}$ and A Stesmans ${ }^{2}$ \\ ${ }^{1}$ Department of Electrical Engineering, University of Leuven, Kasteelpark Arenberg 10, B-3001 \\ Heverlee, Belgium \\ ${ }^{2}$ Department of Physics, University of Leuven, Celestijnenlaan 200D, B-3001 Leuven, Belgium \\ ${ }^{3}$ Imec, Kapeldreef 75, B-3001 Leuven, Belgium
}

DOI link

\begin{abstract}
(200words)
Silicon foils are fabricated using a low-temperature $\left(<150^{\circ} \mathrm{C}\right)$ lift-off process. The electrical activity of traps present in these foils is analyzed by means of deep level transient spectroscopy (DTLS), carried out in parallel with electron spin resonance (ESR) studies to assess the atomic nature of traps. Two hole traps are detected in the as-cleaved samples, one of which is associated with a D-line defect. After vacuum annealing, these traps and the D-line disappear but at the same time, a new hole trap is detected associated with the ESR-revealed $\mathrm{P}_{\mathrm{b} 0}$ recombination center. After chemical removal of a thin Si layer from the crack surface, the ESR signal disappears. This shows that samples fabricated with this method are largely dislocation-free and no electronic levels in the bandgap remain if a layer of a few $\mu \mathrm{m}$ is removed from the crack surface.
\end{abstract}

\section{Background}

In order to reduce material-related costs, there is a need to develop new wafering techniques to produce thin $(<100 \mu \mathrm{m})$ crystalline silicon wafers for photovoltaic (PV) applications.

This work presents a kerf-free wafering process for single crystal silicon which relies only on thermomechanical treatments. The process is named SLIM-Cut (Stress-Induced LIft-off Method).

The process flow is as follows: a layer of a material with a coefficient of thermal expansion (metal or polymer) significantly different from silicon is deposited on top of a bare silicon substrate that could be a few centimeters thick. The system formed by the silicon substrate and the stress-inducing layer later undergoes a thermal process. Upon cooling, the stress-inducing layer will shrink more than the silicon creating a stress field inside the silicon substrate, provided that the bonding is strong enough to withstand this stress.

When the stress reaches a threshold value, the system tends to relax the constraints by propagating a crack either in the stress-inducing layer itself, along the interface, or completely through the substrate (ingot). If the mechanical parameters are chosen carefully, there is a third option for the trajectory of the crack: propagating inside the silicon at a fixed distance from the interface, parallel to the surface, i.e. substrate spalling.

A metal-based approach for the stress inducing layer involves high-temperatures, above the transition temperature for silicon from brittle to ductile [1]. This leads to poor foil quality due to plastic deformation of the material and possible contamination of the foil. Currently, a metal-based approach involving high temperatures is considered not suitable for the fabrication of PV material [2]. Instead, a 
polymer-based approach for the stress inducing layer involves only low-temperature steps (max 150 $\left.{ }^{\circ} \mathrm{C}\right)$, within the brittle regime of $\mathrm{Si}\left(<729^{\circ} \mathrm{C}\right.$ for $\left.(100) \mathrm{Si}\right)$ [3].

Obviously, the quality of the resulting material should be assessed to ensure that this innovative silicon foil production approach does not jeopardize the potential efficiency of the final solar cell. Deep-level transient spectroscopy and electron spin resonance were performed to asses wafer quality in terms of electronic activity and density of defects.

\section{Experimental details}

A notch is inscribed by a laser in a silicon substrate wafer with the following specs: $\mathrm{Cz} ;<100>-$ oriented; p-type, B-doped; resistivity $17-23 \Omega \cdot \mathrm{cm}$; thickness $700 \pm 25 \mu \mathrm{m}$. This notch serves as crack initiation. The wafer is diced in $5 \times 5 \mathrm{~cm}^{2}$ squares. A layer of $700 \mu \mathrm{m}$-thick thermosetting polymer (glass transition temperature $\mathrm{T}_{\mathrm{g}}=70{ }^{\circ} \mathrm{C}$, coefficient of thermal expansion CTE $=80 \mathrm{ppm} / \mathrm{K}$ ) with a thermal expansion coefficient higher than the one of silicon is dispensed on the aforementioned silicon substrate.

The structure is submitted to a thermal process, using either a hotplate or oven, in ambient air at 150 ${ }^{\circ} \mathrm{C}$ for $1 \mathrm{~h}$. In order to propagate the crack from the notch throughout the sample, the bilayer system is dipped in liquid nitrogen. Upon a change in temperature, the overlying layer induces a high stress in the silicon.

The Hutchinson and Suo theory [4]-[5] predicts that, under certain conditions, the crack propagates in a direction parallel to the surface of the substrate and, therefore, it separates a thin layer from the substrate. Finally, a chemical treatment is performed to remove the stress-inducing layer. The resulting $100 \mu \mathrm{m}$-thick structure is flat and can be used for further processing, while the parent substrate can be re-used to fabricate other foils. Figure 1 shows a schematic of the process, while Figure 2 shows a photograph of an actual Si foil after final cleaning.

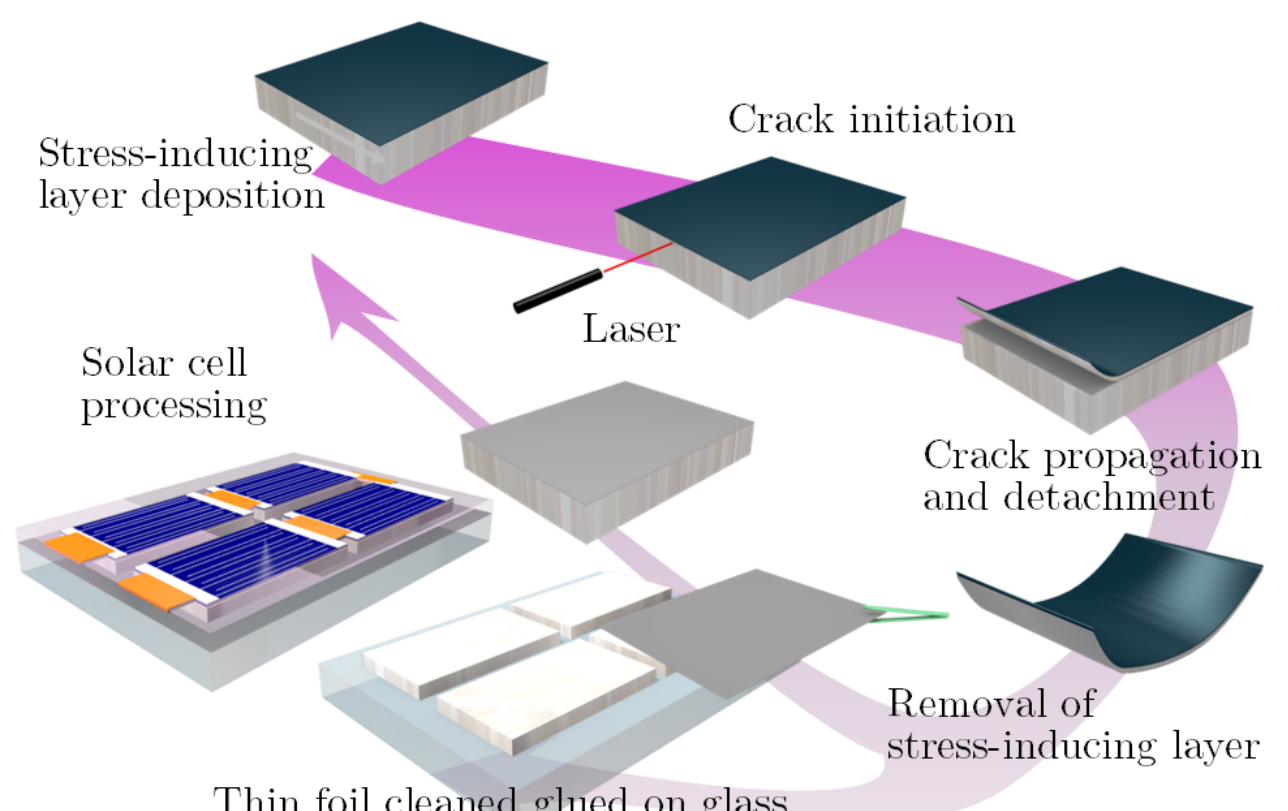

Thin foil cleaned glued on glass

Figure 1: A schematic representation of the SLIM-Cut process. 


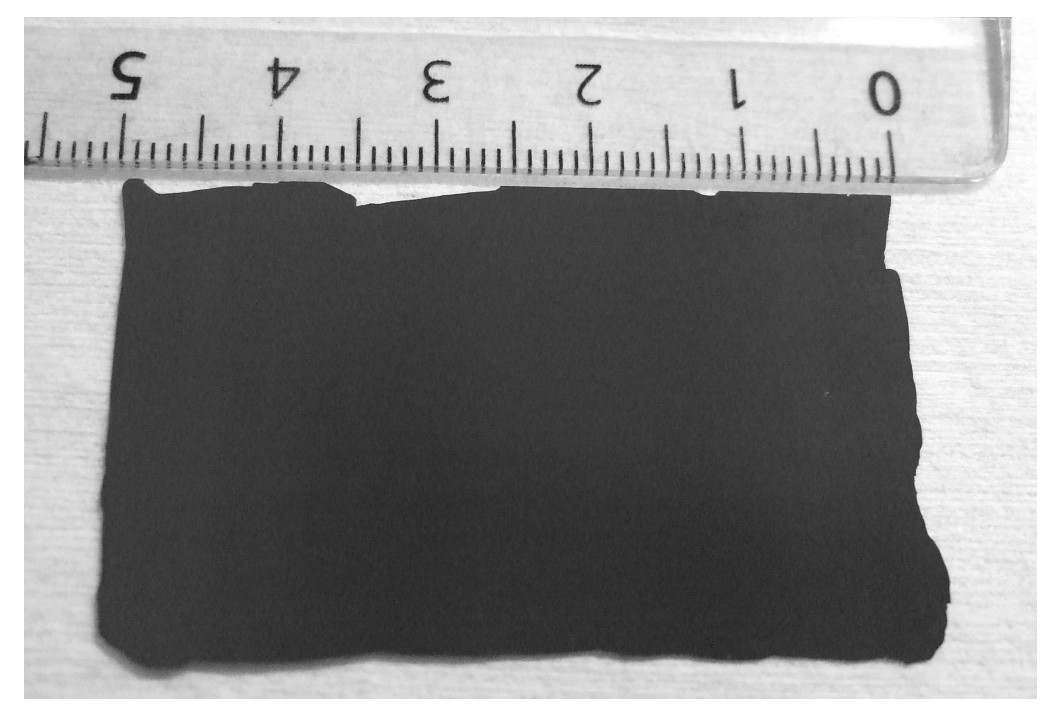

Figure 2: Picture of a (100)Si SLIM-Cut foil after dissolution of the thermoset $\left(3 \times 5 \mathrm{~cm}^{2}\right)$.

Circular Schottky barrier contacts with a diameter of $2.2 \mathrm{~mm}$ were fabricated by evaporating aluminum on the crack surface through a shadow mask. The back-side ohmic contact to the silicon substrate was fabricated by InGa eutectic covered by an In foil. Measurements were performed in a liquid nitrogen flow cryostat using a commercial Fourier-transform DLTS system at the University of Ghent.

Before cooling the samples to $77 \mathrm{~K}$, capacitance-voltage $(\mathrm{C}-\mathrm{V})$ and current-voltage (I-V) measurements were performed at room temperature, sweeping the Schottky barrier from $0 \mathrm{~V}$ to reverse bias and back. The $\mathrm{C}-\mathrm{V}$ measurements were carried out at a fixed modulation frequency $\mathrm{f}$ of 1 $\mathrm{MHz}$ using a Boonton capacitance bridge. From the $1 / \mathrm{C}^{2}$ versus reverse bias $\mathrm{V}_{\mathrm{R}}$ plot in depletion, a value for the silicon doping density was extracted, found to be equal to $\mathrm{N}_{\mathrm{A}}=(1.5 \pm 0.2) \times 10^{15} \mathrm{~cm}^{-3}$. Figure3 shows the depletion depth (W), equivalent to the probed depth, as a function of applied reverse bias.

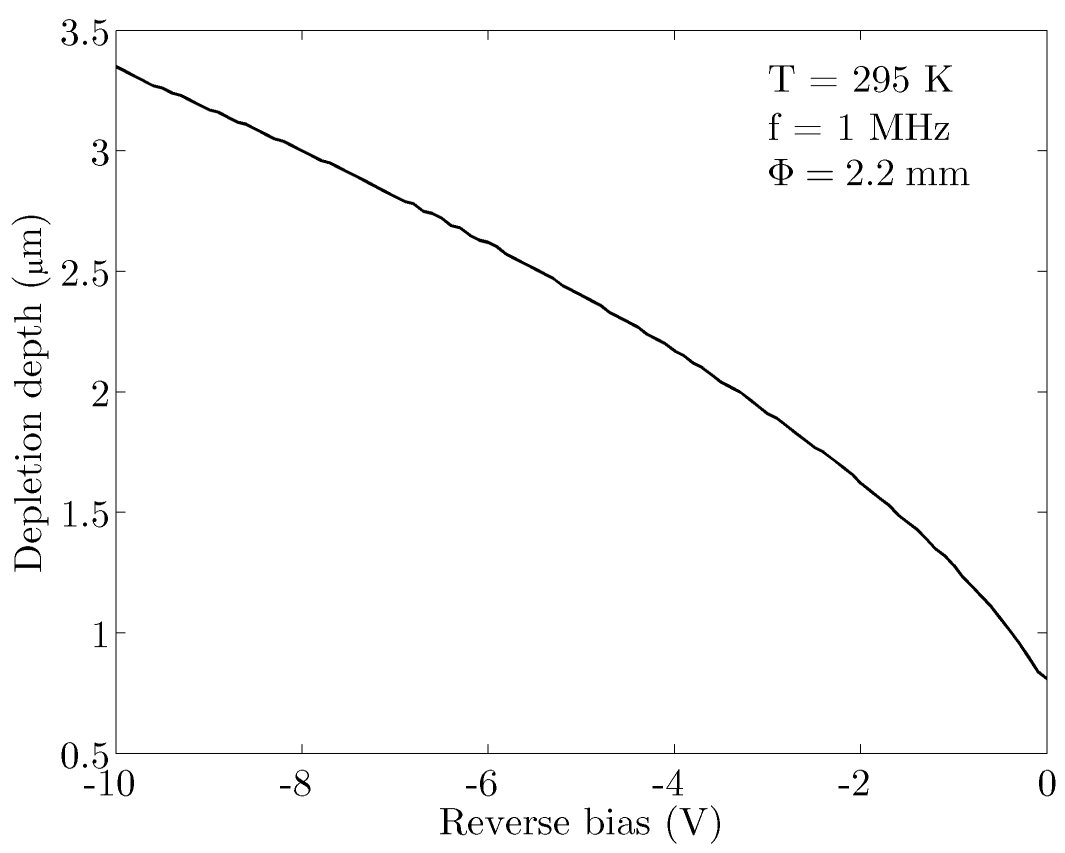

Figure 3: DLTS - Depletion region depth as a function of reverse bias. The probed region is beneath the crack surface. 
DLTS has been performed from $77 \mathrm{~K}$ to room temperature, using a bias pulse from a reverse bias $V_{R}$ to a pulse bias $V_{P}$ for a time $t_{p}$, which is sufficiently long to fill all point defect centra. The pulse period was $\sim \mathrm{t}_{\mathrm{w}}$, with $51.2 \mathrm{~ms}$ as the standard value.

Electron spin resonance (ESR) analysis was performed on silicon foils, lifted-off with the polymerbased approach. This technique is used to probe defects that exhibit paramagnetism as a result of unpaired electron spins. Transitions can be induced between spin states by applying a magnetic field and then supplying electromagnetic energy, usually in the microwave range of frequencies. The resulting absorption spectrum can be analysed on the basis of known signals to identify the type and concentration of defects.

Conventional cw first harmonic absorption spectra $\left(\mathrm{dP}_{\mu \mathrm{r}} / \mathrm{dB}\right.$, where $\mathrm{P}_{\mu \mathrm{r}}$ is the reflected microwave power) K-band $(\sim 20.5 \mathrm{GHz})$ ESR spectra were measured in the adiabatic mode at $\approx 4.4 \mathrm{~K}$. The amplitude $\left(\mathrm{B}_{\mathrm{m}}\right)$ of the applied sinusoidal modulation $\left(\mathrm{B}_{\mathrm{m}} \cos \omega \mathrm{t}\right.$, with $\left.\omega / 2 \pi \sim 100 \mathrm{kHz}\right)$ on top of the applied magnetic field $\mathbf{B}$ and incident microwave power $\left(\mathrm{P}_{n}\right)$ were restricted to levels not causing any (noticeable) signal distortion. Signal averaging was routinely applied $(10-30$ scans $)$ to enhance the signal to noise ratio. A calibrated comounted $\mathrm{Si}: \mathrm{P}$ reference sample [electron spin $\mathrm{S}=1 / 2 ; \mathrm{g}(4.2$ $\mathrm{K})=1.99869 \pm 0.00002]$ was used for $\mathrm{g}$ factor and defect (spin) density determination, where the latter was carried out through double numerical integration of observed signals. The attained absolute and relative accuracies are estimated at $20 \%$ and $\leq 10 \%$ respectively. The field angular dependence of signals was studied for $\mathbf{B}$ rotating in the [011] plane, with $\varphi_{\mathrm{B}}$ (angle of $\mathbf{B}$ with the interface normal $\mathbf{n}$ ) varying over $\sim 90^{\circ}$.

For ESR purposes, slices of $\sim 2 \times 9 \mathrm{~mm}^{2}$ main area were cut from the low-temperature (100)Si SLIMCut foils with their 9-mm edge along a [011] direction; one ESR sample was fabricated from a (111)SLIM-Cut foil. The ESR analyses were performed on a stack (typically $\sim 10$ ) of these slices. The cutting damage (diamond saw) was selectively removed through wet chemically etching using Planar etch. Prior to each ESR observation, the (native) oxide was selectively removed by dipping in aqueous HF solution [HF (49\%): $\left.\mathrm{H}_{2} \mathrm{O} ; 1: 9\right]$.

\section{Results}

First, to identify possible electronic traps, DLTS analysis was performed on as-cleaved (100)SLIMCut foils as well as a sample that was vacuum annealed in order to remove (bulk) hydrogenation of defects (see, e.g., Ref. [6]). Next, results will be presented of ESR analysis on samples that were processed to remove surface and bulk passivation. Both (100) and (111)SLIM-Cut samples were studied by ESR with similar results obtained. Here we will focus on the (100)face data in comparison with obtained DLTS results.

\subsection{DLTS measurements}

The DLTS temperature scan, such as shown in Fig. 4, from $77 \mathrm{~K}$ to $300 \mathrm{~K}$ for an as-cut (100)Si sample typically reveals two clear peaks $\mathrm{H} 1$ and $\mathrm{H} 2$, respectively at around $180-200 \mathrm{~K}$ and $260 \mathrm{~K}$, and a minor $\mathrm{H} 3$ peak around $125 \mathrm{~K}$, corresponding to hole traps in p-type silicon. The trap concentrations are $8 \pm 0.5 \times 10^{12} \mathrm{~cm}^{-3}$ and $4 \pm 0.4 \times 10^{12} \mathrm{~cm}^{-3}$ for $\mathrm{H} 1$ and $\mathrm{H} 2$ respectively.

One can also observe a bias pulse dependence of the peak position and amplitude, suggesting that the underlying deep level centra are no simple point defects, but could correspond to a distribution of deep levels. From the fact that they can be observed from $-10 \mathrm{~V}$ to $-2 \mathrm{~V}$ one can derive that the deep levels are present down to $3 \mu \mathrm{m}$ from the surface, based on the $\mathrm{W}-\mathrm{V}$ plot shown in Figure 3. 


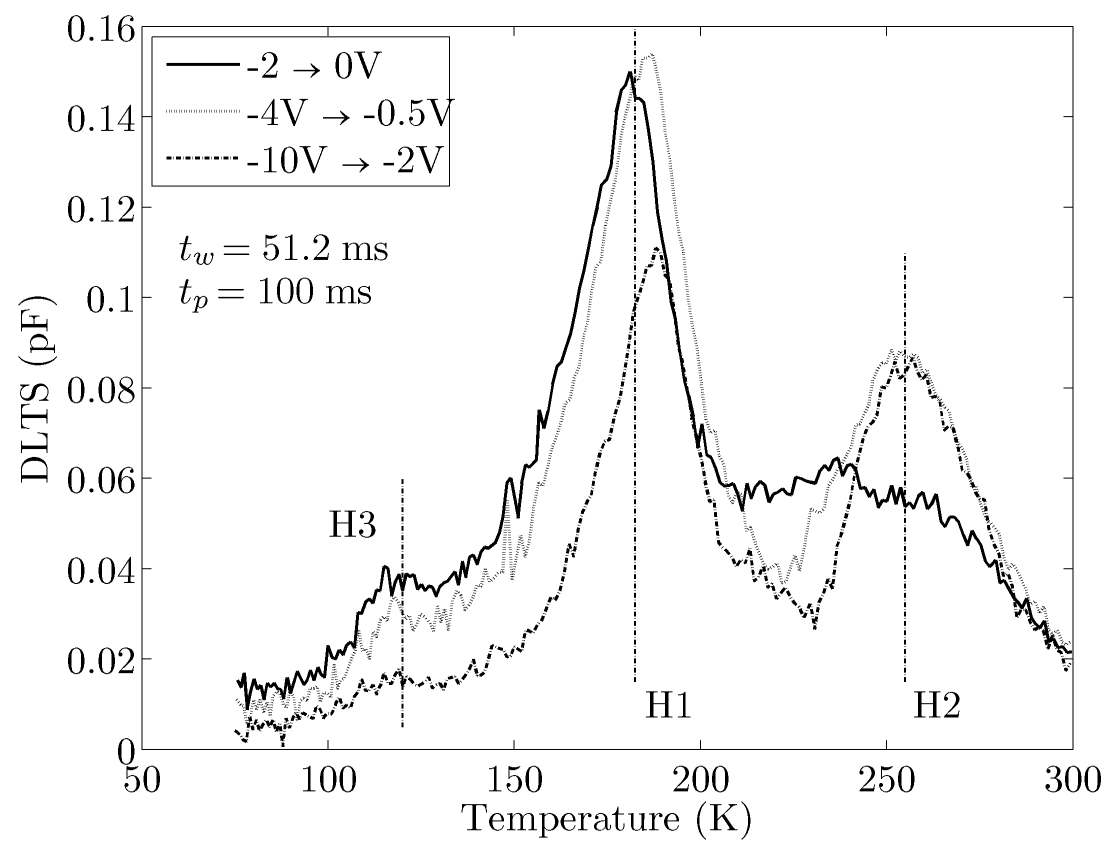

Figure 4: DLTS signals as a function of temperature for different reverse bias measured on a (100)SLIM-Cut sample (crack surface side).

When analyzing the pulse duration dependence of the respective deep levels in Fig. 5a and 5b, one can notice that the $170 \mathrm{~K}$ level behaves as a point defect in the sense that the DLTS amplitude first increases with $t_{p}$, followed by saturation at around $1 \mu \mathrm{s}$. The $\mathrm{H} 2$ peak at $270 \mathrm{~K}$, on the other hand, exhibits a linear increase of the peak height with $\ln \left(\mathrm{t}_{\mathrm{p}}\right)$. This is indicative of an array of extended defects, like the dangling bonds in the core of a dislocation [7]-[10]. Alternatively, it could be point defects aligned in the strain field of an extended defect. Given this logarithmic filling, the trap concentration of $\mathrm{H} 2$ is a lower limit.

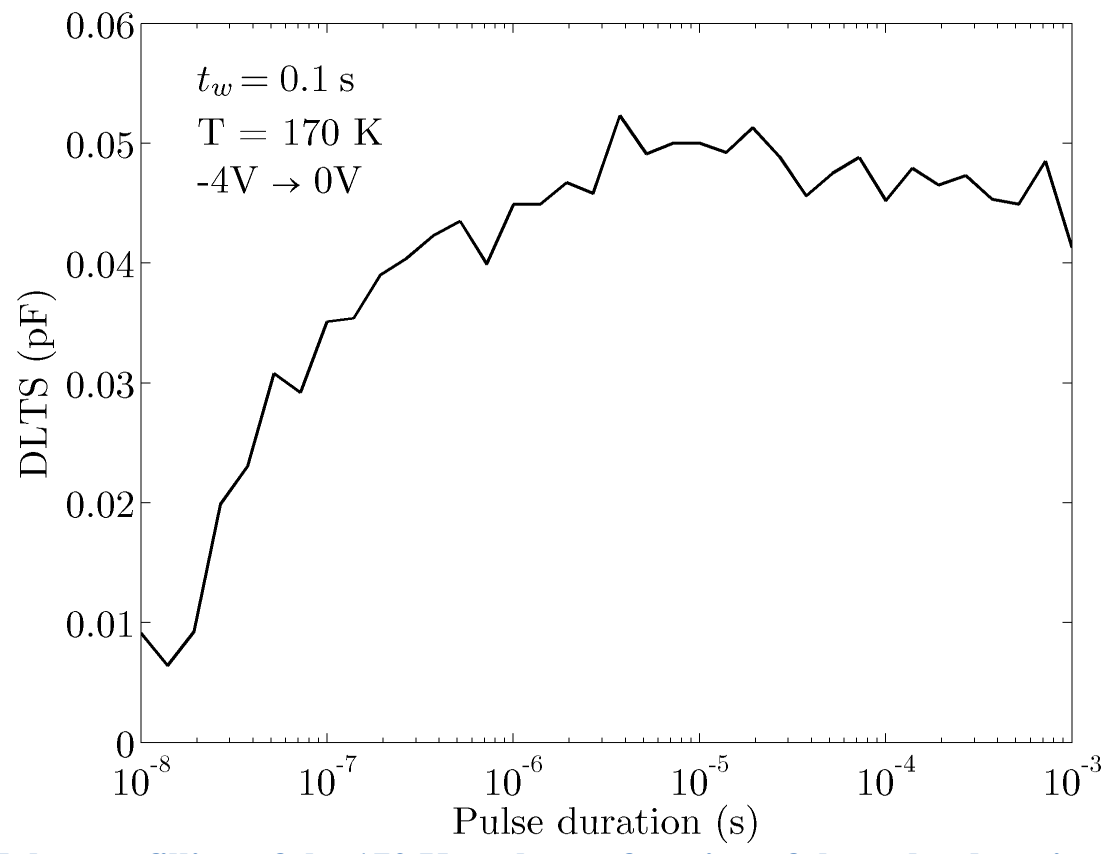

Figure 5a: Hole trap filling of the $170 \mathrm{~K}$ peak as a function of the pulse duration $\mathrm{t}_{\mathrm{p}}$ at a bias pulse from $-4 \mathrm{~V}$ to $0 \mathrm{~V}$ 


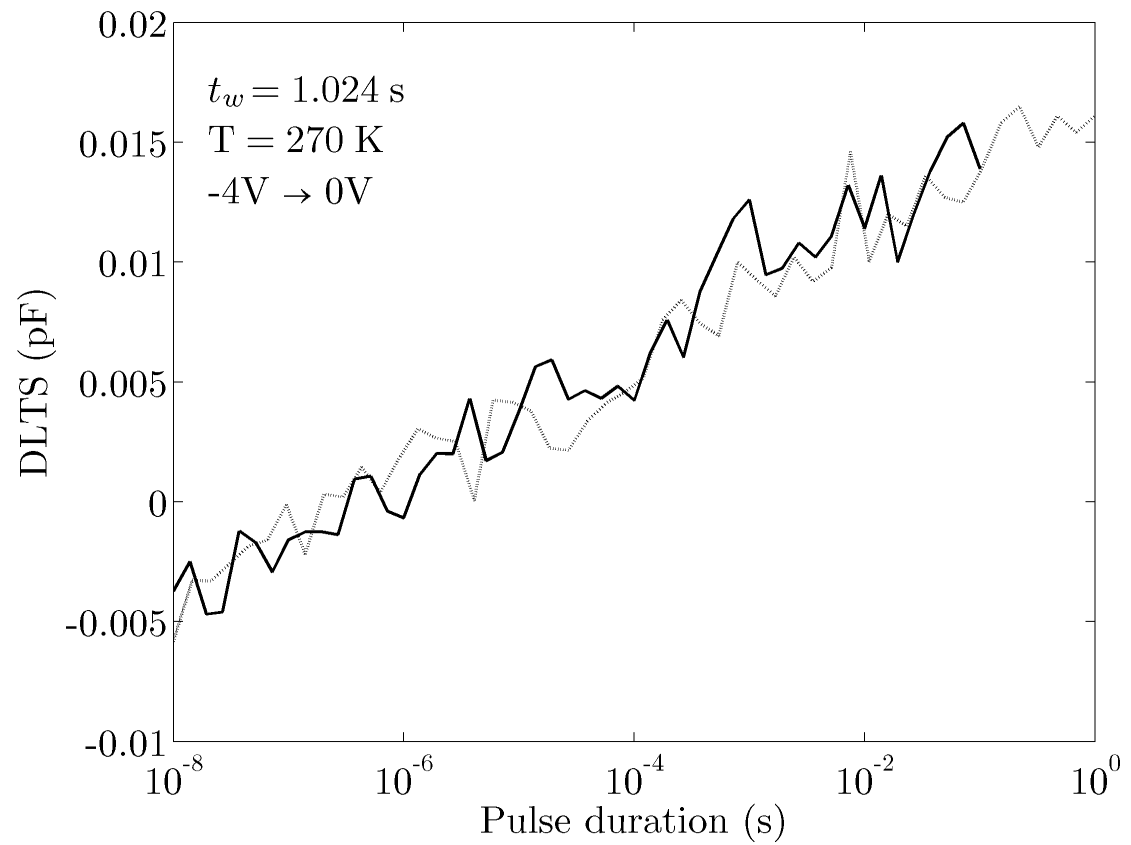

Figure 5b: Hole trap filling of the $270 \mathrm{~K}$ peak as a function of the pulse duration $\mathrm{t}_{\mathrm{p}}$ at a bias pulse from $-4 \mathrm{~V}$ to $0 \mathrm{~V}$.

Plotting the data in an Arrhenius plot (see Figure 6) can give an indication of the value of the electronic level and capture cross-section for each trap. The activation energy $E_{t}$ and hole capture cross section $\sigma_{\mathrm{p}}$ of the "point defect" trap (square and cross symbols) have consistent values $\left(\mathrm{E}_{\mathrm{t}}=\mathrm{E}_{\mathrm{v}}+\right.$ $0.410 \mathrm{eV}$ and $\left.\sigma_{\mathrm{p}}=3.3 \times 10^{-13} \mathrm{~cm}^{2}\right)$ while a wide spread $\left(\mathrm{E}_{\mathrm{t}}=\mathrm{E}_{\mathrm{v}}+0.438 \pm 0.038 \mathrm{eV}\right.$ and $\sigma_{\mathrm{p}}=32.8 \pm$ $29.9 \times 10^{-17} \mathrm{~cm}^{2}$ ) is seen for the "extended defect" trap (diamond and circle symbols).

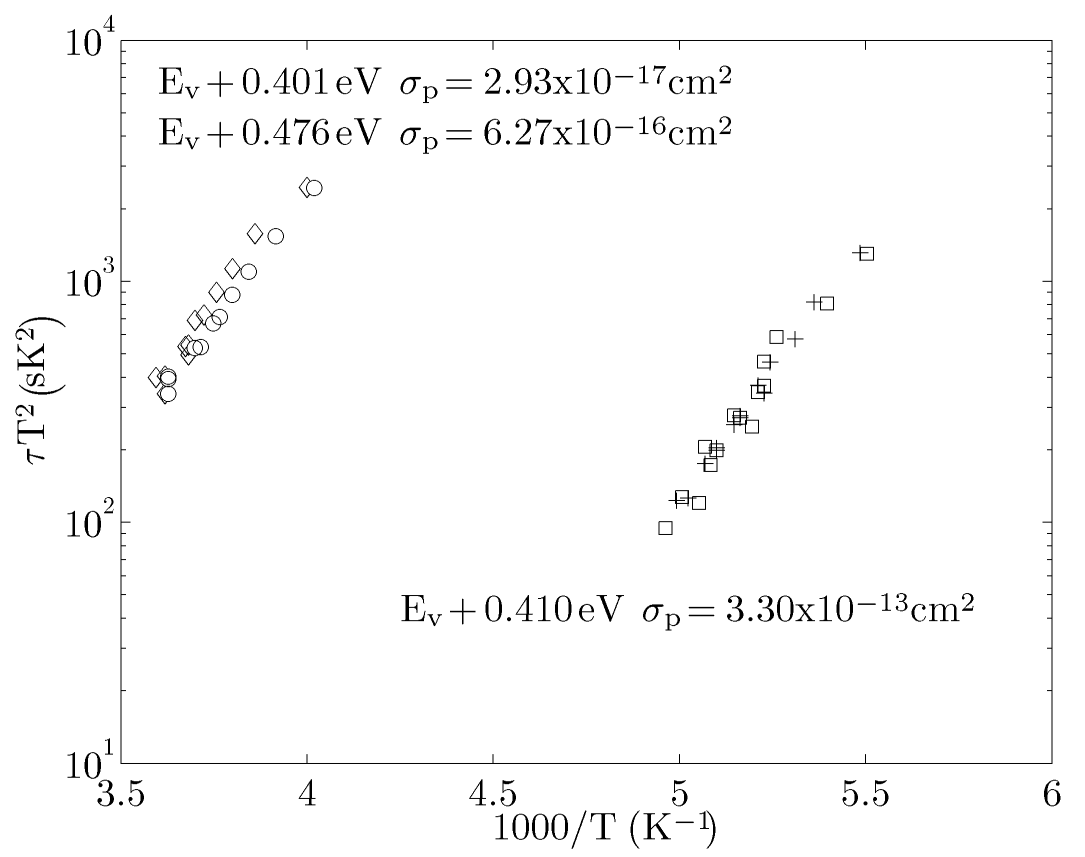

Figure 6: DLTS - Arrhenius plot obtained on an as-fabricated SLIM-Cut sample. 


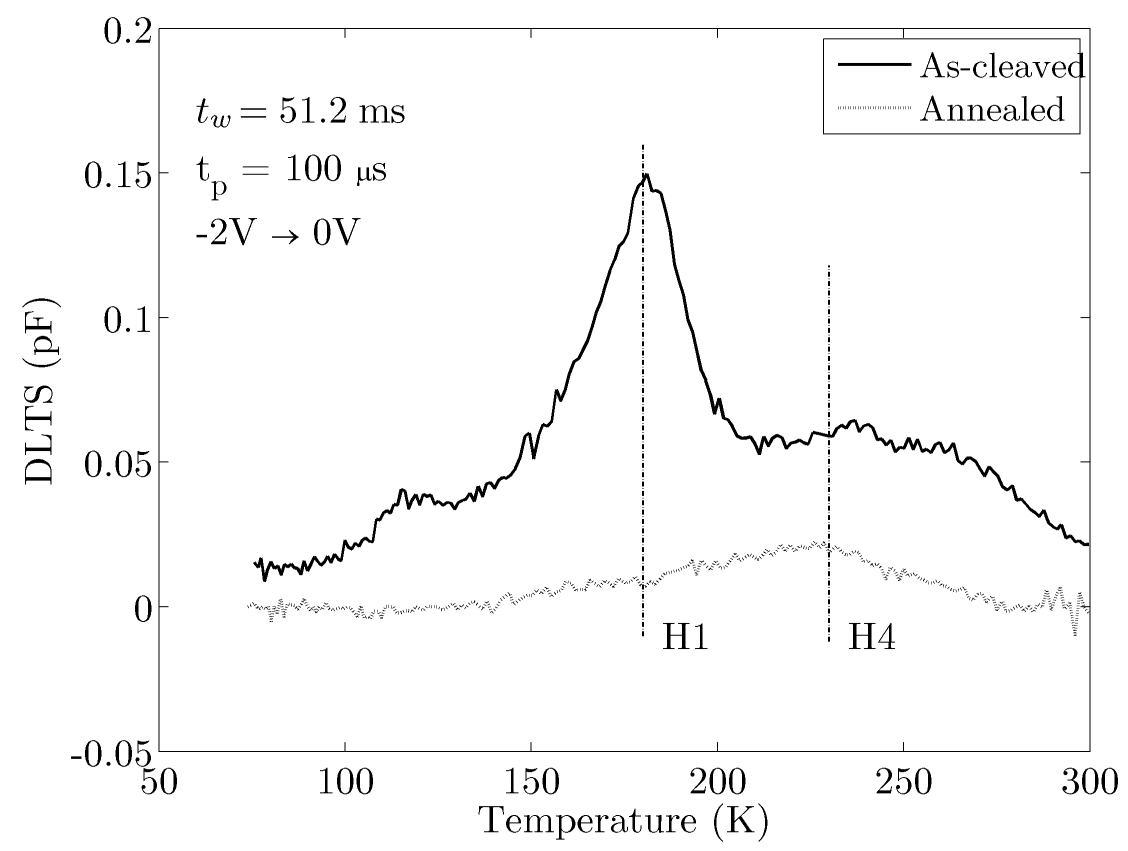

Figure 7: DLTS signals as a function of temperature, before and after annealing. The reduction of the $\mathrm{H} 1$ and $\mathrm{H} 4$ peaks by the anneal treatment is evident.

To maximally reduce any inadvertent influence of hydrogen (passivation of defects), samples were subjected to annealing in vacuum $\left(<5 \times 10^{-6}\right.$ Torr; $\left.606{ }^{\circ} \mathrm{C} ; \sim 2 \mathrm{~h}\right)$ by making use of a mobile conventional electronically stabilized resistance-heated furnace foreseen with a double-walled quartz insert. The corresponding temperature-scan DLTS is compared in Fig. 7 with two as-cut samples. As expected there is a significant reduction of the hole traps after vacuum annealing, for a pulse close to the surface, i.e., from $-2 \mathrm{~V}$ to $0 \mathrm{~V}$. As can be seen, trap $\mathrm{H} 2$ in the as-cleaved sample has nearly completely vanished after annealing, leaving a peak, $\mathrm{H} 4$, at a lower temperature position. Whether it is the reaction product of the annealing of $\mathrm{H} 4$ or a more stable deep level, present as a shoulder in Fig. 4 or the top spectrum of Fig. 7, is not clear for the moment. This requires a more detailed systematic study as a function of annealing temperature and time, which is outside the scope of the present work. Upon the application of a pulse in forward operation, a new hole trap H5, spatially located close to the metal-semiconductor interface, is found in the annealed sample (Fig. 8). The trap concentration for H5 is $2.0 \pm 0.3 \times 10^{11} \mathrm{~cm}^{-3}$, for a pulse duration of 100 microseconds. This H5 trap was not found in an unannealed sample in forward bias. 


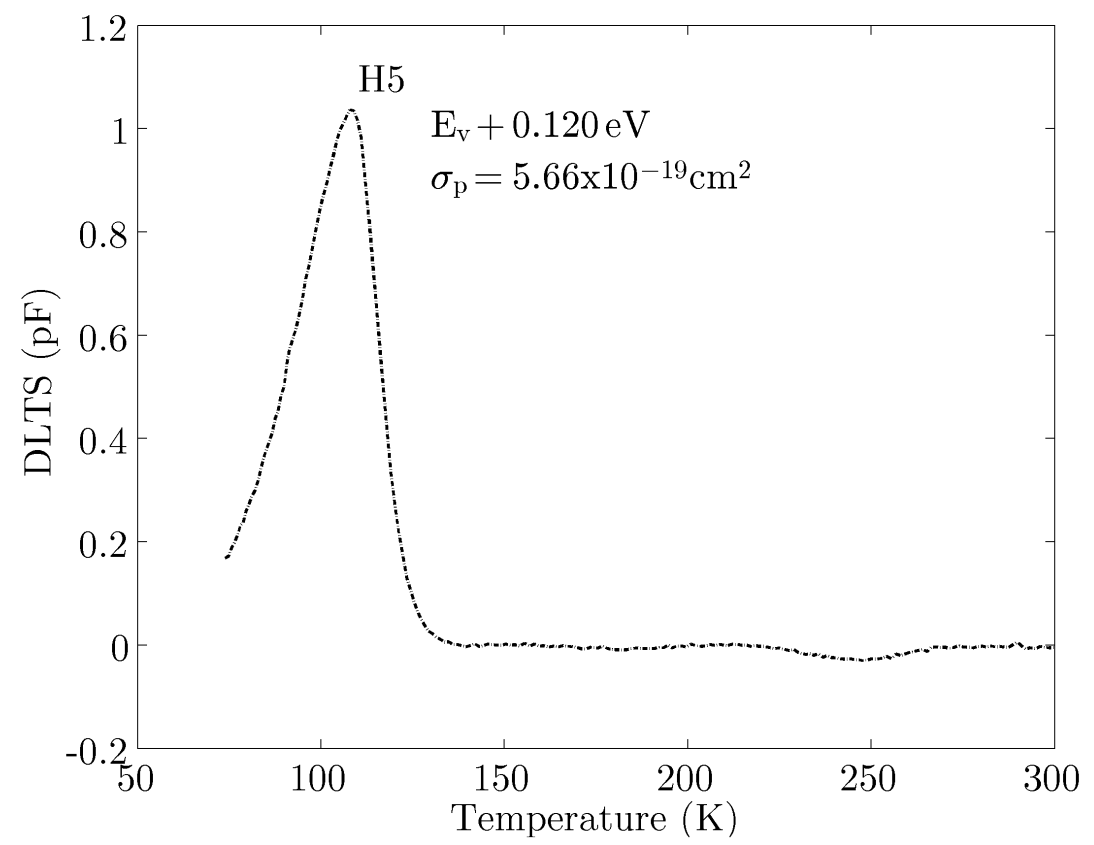

Figure 8: DLTS signals as a function of temperature, measured for different bias values on the annealed sample. A new hole trap $\mathrm{H5}$ is found.

\subsection{ESR measurements}

The main results, in terms of areal densities of the observed types of defects, are summarized in Table 1.

After removal of all oxides, only one single signal is observed: the D-line (a-Si DB in a-Si environment), as shown in the upper part of figure 9. Within experimental sensitivity, no other ESR signals could be traced despite intense ESR signal averaging over a broad magnetic field range.

After a first ESR test on slices without surface oxide, the sample was annealed in vacuum as described in the previous section. After, again dipping in aqueous HF (oxide removal), the D-line was found to have disappeared. Instead, quite surprisingly, now the anisotropic signals are observed from interfacial $\mathrm{P}_{\mathrm{b} 0}$ defects, characteristic for the $(100) \mathrm{Si} / \mathrm{SiO}_{2}$ interface. The $\mathrm{P}_{\mathrm{b} 0}$ defect assignment of the observed signal was demonstrated from angular dependent measurements for $\mathbf{B}$ rotating in the [011] plane, showing branching of the ESR spectrum in three components with corresponding g map in perfect agreement with previous $\mathrm{P}_{\mathrm{b} 0}$ data [11]. As illustrated in Figure 9 (bottom part), it is observed as a single signal at $g=2.0060$ for the configuration $\mathbf{B} / / \mathbf{n}$, in line with the $\mathrm{P}_{\mathrm{b}_{0}}$ signature.

Pertinently, one may remark here that generally, in standard device-grade thermal (100)Si/ $\mathrm{SiO}_{2}, \mathrm{P}_{\mathrm{b} 0}$ is observed in tandem with a second kind of interfacial Si DB type defect, the $\mathrm{P}_{\mathrm{b} 1}$ defect - like $\mathrm{P}_{\mathrm{b} 0}$ also concerning a threefold defected Si atom, but now part of a strained interfacial Si-Si dimer. Despite intensive ESR measurements, the latter defect is not observed. But, on second thought, this does not come as a surprise since, as repeatedly reported before, the defect is not observed in low-temperature (room ambient in the current case) grown (100) $\mathrm{Si} / \mathrm{SiO}_{2}$ structures [12]. Its ESR appearance requires subjection of the structure to higher temperature step. 


\begin{tabular}{|c|ccc|c|}
\hline $\begin{array}{c}\text { Treatment } \\
\text { defect }\end{array}$ & g-value & $\Delta \mathrm{B}_{\mathrm{pp}}(\mathrm{G})$ & $\begin{array}{c}\text { Density } \\
\left(\mathrm{cm}^{-2}\right)\end{array}$ \\
\hline \hline $\begin{array}{c}\text { As cleaved } \\
\text { (all oxides removed) }\end{array}$ & $\mathrm{D}-$ line & 2.0054 & $6.0( \pm 0.1)$ & $8.5( \pm 0.6) \mathrm{E}+11$ \\
\hline $\begin{array}{c}\text { Vacuum anneal } \\
\text { (all oxides removed) }\end{array}$ & $\mathrm{P}_{\mathrm{b} 0}$ & 2.0060 & $6.9( \pm 0.2)$ & $4.3( \pm 0.5) \mathrm{E}+12$ \\
\hline
\end{tabular}

Table 1: Spin densities of observed ESR signals determined through use of a calibrated marker. The $D$ line originates from Si dangling bond (DB) defects in an amorphous environment; $P_{b 0}$ is a characteristic $\mathrm{Si} \mathrm{DB}$ defect at the (100)Si/SiO${ }_{2}$ interface.

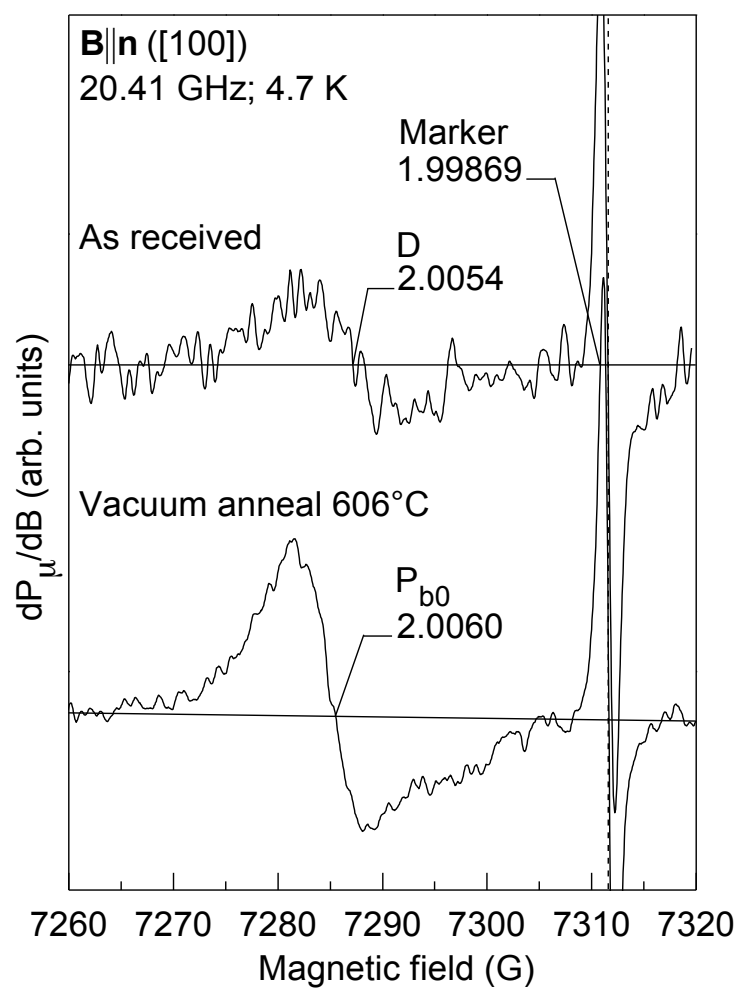

Figure 9: ESR spectra observed on a p-type (100)Si foil obtained by the low-temperature SLIMCut technique. The signal at $\mathrm{g}=1.99869$ stems from a co-mounted Si:P marker sample.

\section{Discussion}

From DLTS experiments on the as-cut material, two dominant deep-level peaks have been identified, which are believed to correspond to a distribution of point defect levels (170 K band) or extendeddefect related levels. Interestingly, the 'line' of diamonds and circles in the Arrhenius plot of Fig. 6 has the same signature as the extended hole trap found in AlN/Si(111) MOS capacitors (Figure 10), which has been ascribed to strain-induced point-defect clusters [13], [14]. In fact, the spectrum of Fig. 4 resembles closely the one of Fig. 1 in Ref. [15], corresponding with a $606{ }^{\circ} \mathrm{C}, 30$ min anneal after 1.2 MeV Si ion implantation. It is well-known that ion implantation introduces excess point defects (vacancies and interstitials) which agglomerate upon annealing. The interstitials thereby undergo a ripening process whereby the size of the cluster increases after prolonged or higher temperature 
annealing and this at the expense of smaller clusters. Eventually, $\{311\}$ extended defects form out of these clusters around $680{ }^{\circ} \mathrm{C}$ [16], which are visible in Transmission Electron Microscopy. At even higher temperatures, these $\{311\}$ defects undergo an unfaulting reaction to form a dislocation loop. Similar type of stress-induced point defect clusters have recently also been reported after laserannealing of ion implanted SiGe-Si heterojunctions [17].

However, as there is no ion implantation nor a thermal budget applied in this case, it is difficult to imagine a source of excess point defects. At the same time, defect wet etching did not reveal the presence of dislocations, so that the origin of the extended defects in Fig. 4 should be different in this case. However, based on the ESR results, a tentative interpretation could point to dangling bonds defects aligned along micro (perhaps, nano) cracks in the silicon substrate at a distance of up to $3 \mu \mathrm{m}$ from the surface, based on the maximum depletion depth at $-10 \mathrm{~V}$ in Fig. 3.

It is also clear that these defects anneal out at $606{ }^{\circ} \mathrm{C}$ from their reduction observed in Fig. 7. At the same time, a new hole trap appear close to the surface. The activation energy of $0.120 \mathrm{eV}$ (above the valence band $\left.\mathrm{E}_{\mathrm{V}}\right)$ is close to the one for the donor state of the divacancy $\left(\mathrm{V}_{2}\right)$ [18], perhaps decorated with oxygen [19].

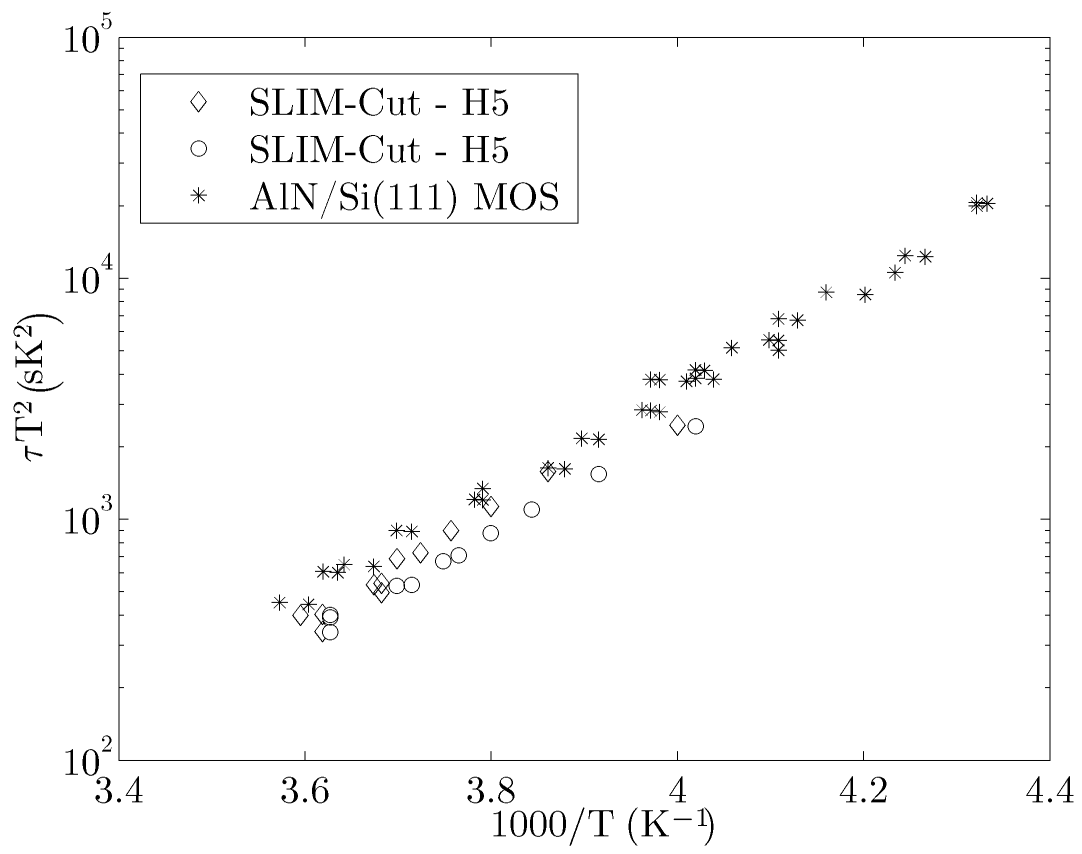

Figure 10: Comparison between DLTS signatures of SLIM-Cut samples (diamond and circle symbols in Fig. 8) and strain-induced point-defect clusters (star symbols) found in AIN/Si(111) MOS capacitors.

The ESR experiments are carried out to analyze any structural damage, and, possibly contamination, in the SLIM-Cut foils through probing occurring paramagnetic (point) defects. In that respect, of course, the most interesting observations would be those performed on the as-manufactured SLIMCut foil with all oxide removed so that all defects within the foil, and only those, are analyzed, including those near its surfaces.

As outlined, only a D-line is observed, stemming from Si DBs in a disordered environment. With the current "cracking off" method applied for SLIM-Cut foil production, that observation may not come as a surprise. Indeed, that signal is virtually always observed -often referred to as the "crack line"after whatever mechanical damage is imposed on c-Si, such as after $\mathrm{Si}$ wafer fracturing (breaking) [20], Si wafer cutting (e.g., by diamond saw) [21], and crushing of c-Si to powder. In these cases, the D signal DBs are pictured as residing in microcracks, mostly along (111) planes [20], in the $\mathrm{Si}$ surface. Also, a D-line like signal has been associated [8] with dislocation defects in c-Si. So the 
current D signal may be associated with Si surface microcracks and/or dislocations. By extension, the D-line DB's may also reside in microvoids.

After vacuum annealing, instead of the $\mathrm{D}$ line, now the $\mathrm{P}_{\mathrm{b} 0} \mathrm{Si} \mathrm{DB}$ defect, characteristic for a $(100) \mathrm{Si} / \mathrm{SiO}_{2}$ interface appears, in quite a substantial density. Clearly, the anneal treatment has thus resulted in the disappearance of some Si disorder. But from where does $\mathrm{P}_{\mathrm{b} 0}$ originate? As any Si oxide has been removed from the SLIM-Cut foil surfaces prior to ESR observations, the $\mathrm{P}_{\mathrm{b} 0}$ signal should not originate from outer foil surface/oxide interfaces. Also, simple conversion of the D-line DBs into "ordered" centers may appear unlikely, as would also be countered by comparison of inferred defects densities (cf. Table 1). The introduction of $\mathrm{P}_{\mathrm{b} 0}$ centers would require some $\mathrm{Si} / \mathrm{SiO}_{2}$-type interface formation. One suggestion then may be that, due to remaining $\mathrm{O}_{2}$ residues in the vacuum ambient, albeit low, some (partial) internal oxidation of microcracks and/or voids has occurred during the 'vacuum' treatment giving rise to incorporation of interfacial $\mathrm{P}_{\mathrm{b} 0}$ centers at hidden interfaces.

Obviously, when residing in inaccessible microcracks and/or voids, it is not surprising that dipping in aqueous $\mathrm{HF}$ solution $\left(\mathrm{SiO}_{2}\right.$ etchant) removing all top oxide but not $\mathrm{Si}$, will not spawn any effect on the defects. Rather, a Si-etchant would be needed. In fact the situation is much similar to the common experience with the removal of Si cutting damage within the context of ESR experimenting [21]: Unlike a Si etchant, HF dipping does not engender an effect here either. The observation of the $\mathrm{P}_{\mathrm{b} 0^{-}}$ type $\mathrm{Si} / \mathrm{SiO}_{2}$ interface defects appears common for oxidized $\mathrm{Si}$ microstructures and $\mathrm{Si}$ nanoparticles [6].

In this interpretation, it may be interesting to attempt to perform some depth profiling of the $\mathrm{P}_{\mathrm{b} 0}$ centers. Indeed, as the defects cannot originate from the outher Si surface where all oxide has been removed, it would be interesting to get an idea about what depth range they would extend. In order to perform such kind of profiling, a (111)Si SLIM-Cut sample was selectively etched off by timed etching from the crack surface-side only. The amount of material removed is $4.45 \mu \mathrm{m}$. Then, as described before, all oxides were removed. On this sample, ESR analysis was not able to detect any signal. It is thus concluded that all D-line Si dangling bond damage is restricted to a surface layer $<=$ $4.4 \mu \mathrm{m}$ thick and, as expected, also confirms the absence of dislocations.

\section{Conclusions}

It is shown that silicon samples fabricated via a low-temperature lift-off method, called also polymerbased SLIM-Cut, show hole traps referable to point defects and strain-induced point-defect clusters, namely $\mathrm{H} 1$ and $\mathrm{H} 4$. These electronic levels have paramagnetic behavior and are associated with a Dline defect.

After vacuum annealing, the $\mathrm{D}$-line defect disappears but the presence of dangling bond $\mathrm{P}_{\mathrm{b} 0}$ centers is detected in the samples. At the same time, $\mathrm{H} 1$ and $\mathrm{H} 4$ traps disappears after vacuum annealing but a new H5 hole trap is detected.

Finally, removing a thin layer of silicon material from the crack surface is found to eliminate all ESR signals which indicates that the cleavage-induced damage remains confined to within a few microns below the crack surface.

\section{Acknowledgments}

The authors wish to thank EC (SUGAR project FP7 $n^{\circ}$ 256752) and IWT (SiLaSol project $n^{\circ}$ 90047) for the financial support to this research. The Flemish Government is also thankfully acknowledged for support through the Methusalem financing.

\section{References}


[1] J. Samuels, S. G. Roberts, and P. B. Hirsch, "The brittle-to-ductile transition in silicon," Materials Science and Engineering: A, vol. 105-106, Part 1, pp. 39-46,1988.

[2] A. Masolin, J. Vaes, F. Dross, R. Martini, A. P. Rodriguez, J. Poortmans, and R. Mertens, "Evidence and characterization of crystallographic defect and material quality after SLiM-Cut process," in MRS Spring Meeting: Symposium C, 2011, pp. 25-29.

[3] R. Martini, M. Gonzalez, F. Dross, A. Masolin, J. Vaes, D. Frederickx, and J. Poortmans, "Epoxy-Induced Spalling of Silicon," Energy Procedia, vol. 27, pp. 567-572, 2012.

[4] J. W. Hutchinson and Z. Suo, "Mixed mode cracking in layered materials," Advances in applied mechanics, vol. 29, p. 191, 1992.

[5] Z. Suo and J. W. Hutchinson, "Steady-state cracking in brittle substrates beneath adherent films," International Journal of Solids and Structures, vol. 25, pp. 1337-1353, 1989.

[6] M. Jivanescu, A. Stesmans, R. Kurstjens, and F. Dross, "Interface nature of oxidized singlecrystal arrays of etched Si nanowires on (100)Si," Applied Physics Letters, vol. 100, pp. 082110 $082110-4,2012$.

[7] L. C. Kimerling and J. R. Patel, "Defect states associated with dislocations in silicon," Applied Physics Letters, vol. 34, pp. 73-75, 1979.

[8] W. Schröter, J. Kronewitz, U. Gnauert, F. Riedel, and M. Seibt, "Bandlike and localized states at extended defects in silicon," Phys. Rev. B, vol. 52, pp. 13726-13729, 1995.

[9] D. Cavalcoli, A. Cavallini, and E. Gombia, "Defect states in plastically deformed n-type silicon," Phys. Rev. B, vol. 56, pp. 10208-10214, 1997.

[10] W. Schröter and H. Cerva, "Interaction of Point Defects with Dislocations in Silicon and Germanium: Electrical and Optical Effects," Solid State Phenomena, vol. 85-86, pp. 67-144, 2002.

[11] A. Stesmans and V. V. Afanas'ev, "Electron spin resonance features of interface defects in thermal (100)Si/SiO2" J. Appl. Phys. 83, 2449 (1998)

[12] K. Clémer, A. Stesmans, V. V. Afanas'ev, L. F. Edge, and D. G. Schlom, "Paramagnetic point defects in (100)Si/LaAlO 3 structures: Nature and stability of the interface," J. Appl. Phys. 101, 034516 (2007).

[13] E. Simoen, D. Visalli, M. Van Hove, M. Leys, and G. Borghs, "A deep-level analysis of Ni$\mathrm{Au} / \mathrm{AlN} /(111) \mathrm{p}+-\mathrm{Si}$ metal-insulator-semiconductor capacitors," Journal of Physics D: Applied Physics, vol. 44, p. 475104, 2011.

[14] E. Simoen, D. Visalli, M. Van Hove, M. Leys, P. Favia, H. Bender, G. Borghs, A. P. D. Nguyen, and A. Stesmans, "Electrically active defects at AIN/Si interface studied by DLTS and ESR," physica status solidi (a), vol. 209, pp. 1851-1856, 2012.

[15] J. L. Benton, K. Halliburton, S. Libertino, D. J. Eaglesham, and S. Coffa, "Electrical signatures and thermal stability of interstitial clusters in ion implanted Si," Journal of Applied Physics, vol. 84, pp. 4749 -4756, Nov. 1998.

[16] J. L. Benton, S. Libertino, P. Kringhøj, D. J. Eaglesham, J. M. Poate, and S. Coffa, "Evolution from point to extended defects in ion implanted silicon," Journal of Applied Physics, vol. 82,,pp. $120-125,1997$.

[17] M. H. Yu, L. T. Wang, T. C. Huang, T. L. Lee, and H. C. Cheng, "The Strained-SiGe Relaxation Induced Underlying Si Defects Following the Millisecond Annealing for the 32 nm PMOSFETs," J. Electrochem. Soc., vol. 159, pp. H243-H249, 2012.

[18] F. D. Auret and P. M. Mooney, "Transient capacitance study of defects introduced by electronbeam deposition of metals on p-type silicon," J. Appl.Phys., vol. 55, pp. $984-987,1984$.

[19] M. A. Trauwaert, J. Vanhellemont, H. E. Maes, A. M. Van Bavel, G. Langouche, and P. Clauws, "Low-temperature anneal of the divacancy in p-type silicon: A transformation from V2 to VxOy complexes?," Applied Physics Letters, vol. 66, pp. 3056 -3057, 1995.

[20] B. P. Lemke and D. Haneman, "Dangling bonds on silicon," Phys. Rev. B, vol. 17, pp. 1893$1907,1978$.

[21] A. Stesmans, J. Braet, J. Witters, and R. F. Dekeersmaecker, "X and K band ESR study of the $P_{b}$ Interface centres in thermally oxidized p-type (001)Si wafers at low temperatures and influence of medium-dose As+ ion implantation," Surface Science, vol. 141, pp. 255-284, 1984. 